\title{
An evaluation of the nature and level of musculoskeletal imaging training in physiotherapy educational programme in Nigeria
}

Ogochukwu Kelechi Onyeso ( $\sim$ kzetfeank@yahoo.com )

University of Nigeria - Enugu Campus https://orcid.org/0000-0002-8821-4075

Joseph 0 Umunnah

Nnamdi Azikiwe University Faculty of Health Science and Technology

Charles Ikechukwu Ezema

University of Nigeria

Joseph A Balogun

Chicago State University

Chigozie Uchenwoke

University of Nigeria

Maduabuchukwu Joseph Nwankwo

Nnamdi Azikiwe University Faculty of Health Science and Technology

Kayode Israel Oke

University of Benin

Bashir Bello

Bayero University College of Health Sciences

Ifeoma Blessing Nwosu

Nnamdi Azikiwe University Faculty of Health Science and Technology

Mishael E. Adje

Trier University of Applied Sciences

\section{Research article}

Keywords: Musculoskeletal System, Musculoskeletal Imaging, Diagnostics Imaging, Clinical Decision Making, Physiotherapy Education, Doctor of Physical Therapy, Nigeria

Posted Date: January 20th, 2020

DOI: https://doi.org/10.21203/rs.2.17163/v2

License: (c) (i) This work is licensed under a Creative Commons Attribution 4.0 International License.

Read Full License 
Version of Record: A version of this preprint was published at BMC Medical Education on August 5th, 2020. See the published version at https://doi.org/10.1186/s12909-020-02183-5. 


\section{Abstract}

Background: Previous studies have shown that deficiency in training may lead to inappropriate utilisation of diagnostic imaging among healthcare professionals, thus, raising concerns about patient safety and economic cost. This study aimed to evaluate the nature and level of musculoskeletal imaging (MI) training received by physiotherapists who graduated from Nigerian universities and completed the oneyear mandatory internship.

Methods: An online version of the Physiotherapist Musculoskeletal Imaging Profiling Questionnaire (PMIPQ), which was previously validated, was administered to all eligible physiotherapists identified through the database of the Medical Rehabilitation Therapist Board's (MRTBN). Data were obtained on demographics, nature, and level of training on various MI modalities using the PMIPQ. Descriptive statistics, Friedman's ANOVA, and Kruskal-Wallis tests were used for the data analysis at $\mathrm{P} \leq 0.05$.

Results: The results showed that only $10.0 \%$ of the respondents had a standalone undergraduate course in $\mathrm{MI}, 92.8 \%$ did not have any $\mathrm{MI}$ clinical posting exposure during the internship, and $67.3 \%$ had never attended any MI workshop. There was a significant difference in the level of training received across various $\mathrm{MI}$ modalities $[X 2(15)=1285.899 ; P=0.001]$. However, there was no significant difference in the level of Ml training across the institutions $(P=0.36)$. The study participants with Doctor of Physiotherapy (DPT) education were better trained in MI than their counterparts with a bachelor's degree $(P=0.047)$.

Conclusions: The self-reported level of MI training among the respondents was deficient, but the knowledge of X-ray was significantly higher than other MI modalities. Based on the overall findings in this study, we recommend that diagnostic imaging contents be introduced early in the current and future physiotherapy training programmes.

\section{Background}

The physiotherapy profession focuses on maximising movement and functional ability in people with risk of physical impairment and movement dysfunction due to aging, injury, diseases, musculoskeletal disorders, or environmental factors, throughout their lifespan [1]. A comprehensive musculoskeletal system assessment is imperative for physiotherapy-practise [2]; hence, musculoskeletal imaging (MI) is useful to physiotherapists, especially, as a first-contact musculoskeletal care provider $[3,4,5]$. Ml offers physiotherapists support in clinical-decision and a broader perspective when planning treatment interventions [6].

The dramatic increase in the demand for diagnostic imaging has necessitated a comprehensive review of its use and implications for healthcare systems $[4,7,8]$. Over-exposure of patients to radiation hazards and economic wastages are some of the problems with inappropriate and overutilisation of imaging services $[9,10]$. Ultimately, the root cause of inappropriate use of imaging may be the nature and content of clinical education received by healthcare practitioners [8]. A study had raised the question of whether physiotherapists are adequately educated regarding imaging referral [5]. 
However, there is evidence that a well-trained physiotherapist can utilise $\mathrm{Ml}$ appropriately as an autonomous provider or within a multidisciplinary team in both the military and civilian populaces $[4,11,12]$. Specifically, physiotherapists in the United States (US) military have been practicing for over four and half decades as direct access providers, with diagnostic imaging rights [11]. The availability of diagnostic studies to physiotherapists vary across countries (Practise Acts) and practise settings [2,7]. In Nigeria, the Medical Rehabilitation Therapists Act, M9 LFN 2004, does not prohibit physiotherapists from the utilisation of MI in clinical practise [2]. Similarly, physiotherapists are currently utilising MI in Australia, Canada, the United Kingdom (UK), the Netherlands, Norway, South Africa, and some parts of the US[4].

Nonetheless, the Ml referral-right varies across practise settings in Nigeria. It seems that private institutions grant more MI referral-right to physiotherapists than government establishments. An unpublished online survey reported that $79.8 \%$ of the physiotherapists in Nigeria have MI referral-right in their practise-settings. Generally, physiotherapists in Nigeria have unrestricted access to MI films and radiologists' reports in the patient's case folder and can integrate the results into their clinical decisionmaking.

Concurrent with the emerging first contact, extended scope, advanced physiotherapy practises, and diagnostic referral rights $[4,12,13]$, many countries have started expanding their entry-level physiotherapy curriculum to align with prevailing standards in physiotherapy education and practise $[2,6,14]$. The physiotherapy programme accreditation standards in the US and the minimum entry-level benchmark in Nigeria now include specific criteria related to diagnostic imaging $[2,4]$.

Physiotherapy training institutions are responsible for preparing their students with knowledge of MI for clinical practise $[7,15]$. Training in MI modalities such as radiography (X-ray), computed tomography (CT) scan, magnetic resonance imaging (MRI), scintigraphy, ultrasound scan (USS), and dual-energy X-ray absorptiometry (DEXA) is relevant for entry-level physiotherapy programme in view of the emerging firstcontact practise $[4,16]$.

There is no gainsaying that $\mathrm{Ml}$ is useful to physiotherapists for evaluation of the severity of injuries, healing processes, and treatment outcomes [6]. For instance, the USS has moved from the radiology suite to the point-of-care, where physiotherapists can perform real-time diagnostic musculoskeletal sonography [17]. The MRI can distinguish subtle musculoskeletal pathologies such as stress fracture, which may have consequences for physiotherapy plan of care [5]. The DEXA scan is a prerequisite for spinal manipulation in geriatrics [16]. The scintigraphy and CT scan can rule out musculoskeletal neoplasm, which may contraindicate some physiotherapy modalities [5]. Nonetheless, MI is useful to physiotherapists for research and educational purposes [6].

The entry-level physiotherapy education in Nigeria adopts a medical model that involves premedical (natural sciences), medical, and core physiotherapy (preclinical and clinical) courses. In this model, the MI contents can be delivered in two ways: the medical-track and standalone courses [16]. Medical-tracks are noncore Ml courses that offer knowledge of Ml through clinical correlates - for example, discussing chest radiographs during cardiopulmonary physiotherapy, exploring MRI of the lumbar spine during 
classes on low back pain or observing USS for rotator-cuff pathology during orthopaedics classes. However, standalone Ml courses are dedicated solely for knowledge and skill in the utilisation of $\mathrm{Ml}$ to aid assessment of various regions of the human body.

Medical-tracks with MI correlates have always been a part of the Nigerian physiotherapy curricular outline [18]. Nevertheless, emphasis on Ml differs across institutions, and standalone Ml courses are lacking in many institutions. The National Universities Commission (NUC) has recently approved the Doctor of Physical Therapy (DPT) programme, as the minimum benchmark for entry-level physiotherapy education in Nigeria [2]. In addition to the medical-tracks, the six-year DPT curriculum provided for a unified standalone Ml course by the first semester of the penultimate year.

Currently, the onus lies on the Medical Rehabilitation Therapists Board of Nigeria (MRTBN) to update the accreditation requirements and mandate the educational institutions to implement the DPT curriculum. Aside from the entry-level and the mandatory post-entry-level clinical internship programmes, physiotherapists in Nigeria are opportune to acquire MI training through the relevant postgraduate and continuous professional development (CPD) programmes.

This study sets out to evaluate the nature and level of Ml training received by physiotherapists who graduated from Nigerian universities and completed the one-year mandatory internship. The findings from the study will identify areas of MI deficiencies and will have implications for the implementation of the DPT curriculum in Nigeria.

\section{Methods}

\section{Study design and sample selection}

This investigation was a cross-sectional study of Nigerian physiotherapists using an online survey method. The population of the study comprised of all MRTBN registered Nigerian-trained physiotherapists currently practicing in the country $(N=4583)$ [19]. Purposive sampling technique was used to select eligible participants from the updated MRTBN database. The inclusion criteria for the study were being (1) an entry-level graduate of an MRTBN and NUC accredited university; (2) completion of the one-year internship programme at an accredited hospital; and at least one-year post-internship clinical experience; (3) currently licenced and practicing physiotherapy in Nigeria. Participants' eligibility was determined by juxtaposing the three inclusion criteria with their information held at the MRTBN database. A total of 2308 physiotherapists were eligible to participate in the study.

\section{Sample size estimation}

Yamane [20] formula $\left(\mathrm{n}=\mathrm{N} /\left[1+\mathrm{N}\{e\}^{2}\right]\right)$ was used to calculate the sample size from the finite population $(N)=4583$, at the level of significance $(e)=0.05$, the calculated sample size $(n) \sim 368$.

\section{Research instrument}


The instrument used for data collection in this study was the Physiotherapist Musculoskeletal Imaging Profiling Questionnaire (PMIPQ). The face, content, and criterion validity - psychometric properties of the research questionnaire had previously been evaluated in a similar population and found to be appropriate [2]. The internal consistency ( $\alpha$-score) and the two-week test-retest reliability ( $\rho$-score) across the domains were: part C ( $a=0.731, \rho=0.973)$, part D $(a=0.737, \rho=0.979)$, part E $(a=0.446, \rho=0.842)$ and part F ( $a$ $=0.796, \rho=0.716)$.

The present study utilised parts A to C of the PMIPQ. Part A sought demographic information such as; age, sex, licence renewal history, years of practise, the region of practise, practise setting, employment cadre, the specialty of interest, educational background, and CPD. Part B collected pertinent data on respondent's undergraduate, internship, workshop, and postgraduate training in MI: first-time instruction, teaching methods, duration, personnel providing MI instruction, and type of hands-on experiences. Part C of PMIPQ assessed the level of training on referral and utilisation of results from different MI modalities such as X-ray, MRI, CT scan, ultrasound, scintigraphy, and DEXA. The complete version of PMIPQ is available on https://doi.org/ 10.4102/sajp.v75i1.1338.

\section{Scoring of the instrument}

Parts $A$ and $B$ of the PMIPQ were closed-ended questions with multiple-choice options obtained on a nominal scale. Part $\mathrm{C}$ obtained the self-reported level of training of various MI modalities, using a fivepoint Likert scale: $1=$ poor, $2=$ fair, $3=$ good, $4=$ very good and $5=$ excellent.

\section{Procedures for data collection}

The PMIPQ was administered online using a uniform resource locator (URL). The URL to the online survey was emailed to all the eligible respondents in the MRTBN database. Three successive reminders were sent to the initial recipients after two days, four days an one week. The participants were told to ignore the reminders if they have completed the questionnaire once. The objectives of the study were clearly explained in the informed consent form attached as the first page of the online questionnaire and endorsed by each participant. The closing paragraph of the consent form contained a statement asking the participants if they were willing to grant their consent to partake in the study. A participant must click the "yes" button to proceed to the survey or choose the "no" button and exit the survey.

The software was programmed to redirect the respondent to complete all the compulsory fields before the survey can be submitted. An appreciation page appeared following a successful submission. A programming syntax was imbedded in the software to track and discard entries from ineligible respondents or multiple entries from eligible respondents. This technological intervention helped in minimizing the perennial problems of the missing questionnaire, incomplete data, computation of questionnaire scores or responses, and eligibility of respondents using the demographic variables. The instrument was hosted online for 30 days, between March and April 2019.

\section{Data analysis}


The survey database was downloaded and analysed with SPSS 20 software (SPSS, Chicago, IL, US). Descriptive statistics of frequency (percentage), median (interquartile range), and mean (standard deviation) were used to summarise the data. The data set was screened for normality using the ShapiroWilk's test and Mauchly's test to determine whether the assumption of sphericity was met. The findings revealed that the data were not normally distributed and violated the assumption of sphericity. Consequently, non-parametric inferential statistics were carried out using Friedman's ANOVA followed by Wilcoxon signed-rank (Bonferroni adjusted) post hoc test, and Kruskal-Wallis with Dunn-Bonferroni post hoc test when a significant difference is obtained. The level of significance was set at an alpha level of 0.05 .

\section{Ethical consideration}

Before the commencement of the study, ethical approval was obtained from the Health Research and Ethics Committee of the Faculty of Health Sciences and Technology, Nnamdi Azikiwe University, Nnewi Campus, Nigeria. The reference number is ERC/FHST/NAU/2018/198. The respondents signed informed consent before proceeding to the survey.

\section{Results}

Out of the 2308 emails that were sent, 2125 successfully delivered, while 183 failed to deliver. After hosting the survey online for 30 days, 436 entries were received - a response rate of $20.5 \%$. However, 400 questionnaires devoid of missing data were used for data analyses.

The respondents were 275 males and 125 females. The demographic characteristics of the respondents were shown in Table 1 . The average age was $33 \pm 8$ years, and the practise experience was $8 \pm 7$ years. The majority $(46.3 \%)$ of the respondents practised in the orthopaedics unit, followed by $21.5 \%$ in neurology, and only $2.0 \%$ practised in the geriatric specialty. The preponderance $(70.0 \%)$ of the respondents possessed a bachelor's degree in physiotherapy, while a few $(2.0 \%)$ had a DPT, $22.3 \%$ had M.Sc., and $5.7 \%$ had a Ph.D.

The result of this study showed that $74.3 \%$ of the respondents received training in at least one $\mathrm{Ml}$ modality during their undergraduate training. A Venn diagram (Figure 1) was used to illustrate the proportion of the respondents that had a standalone course $(10.0 \%)$, medical track courses $(50.8 \%)$, both (13.5\%) and no Ml content (25.7\%). The findings showed that $35.5 \%$ of the respondents during their undergraduate training were instructed with a mix of theory and practical methods. First-time instruction in MI was mainly in the third (22.5\%) or fourth year $(29.0 \%)$ of undergraduate education. Altogether, $44.0 \%$ of the respondents were taught by radiologists, but $42.0 \%$ did not have clinical posting exposure at the Diagnostic Imaging Department. The majority (95.5\%) of the respondents were not taught musculoskeletal USS at that level (Table 2).

Most of the respondents (51.5\%) were trained on how to incorporate MI in clinical decision-making during the internship programme. At that level, training was under the direct supervision of the physiotherapists, 
as reported by $39.0 \%$ of the respondents. A total of $92.8 \%$ of the respondents did not undergo rotational out-posting experience at the Diagnostic Imaging Department. Consequently, 95.5\% did not have handson training in musculoskeletal USS during their internships (Table 2). At the postgraduate level, only a few $(9.8 \%)$ of the respondents had a standalone Ml course, $53.6 \%$ reported that they were not taught or that imaging did not apply to their programme (Table 2). Where appropriate, the first time instruction in MI during postgraduate was either in the first $(22.3 \%)$ or second $(24.1 \%)$ semesters. Most of the respondents did not have clinical posting (91.1\%) or hands-on training in musculoskeletal USS (95.5\%) during their postgraduate study.

One of the avenues healthcare workers update their knowledge and skills is by attending relevant workshops (CPDs). Table 2 showed that $67.3 \%(n=269)$ of the respondents have never attended an MI workshop. Among the $32.7 \%$ that had participated in diagnostic imaging workshops, many attended only once (Figure 2). Only $17.5 \%$ had practical MI training during the workshops. Specifically, $9.5 \%$ had a hands-on musculoskeletal USS.

The respondents' self-reported level of training across various MI modalities was shown in figure 3 . The level of training was rated as follows: $X$-ray = good; MRI and CT scan = fair; USS, scintigraphy, and DEXA $=$ poor. Friedman's ANOVA (Table 3 ) showed that there was a significant difference in the level of training received by the respondents across the MI modalities $(\chi 2(15)=1285.90, p<0.001)$.

Wilcoxon signed-rank; Bonferroni adjusted post hoc analysis showed that there was a significant difference in the level of training between the following MI modalities: $X$-ray vs.; MRI $(p<0.001)$, CT scan $(p<0.001)$, USS $(p=0.015)$, scintigraphy $(p<0.001)$, and DEXA $(p<0.001), M R /$ vs.; CT scan $(p<0.001)$, USS ( $p<0.001)$, scintigraphy $(p<0.001)$, and DEXA $(p<0.001), C T$ scan vs.; USS $(p<0.001)$, scintigraphy $(p<0.001)$, and DEXA $(p<0.001)$. However, there was no significant difference between the level of training received on USS vs. scintigraphy $(p=4.80)$ or DEXA $(p=0.15)$ or scintigraphy vs. DEXA $(p=$ $0.11)$.

Adjusted for higher educational qualification, internship training, workshops, specialty, practise setting and years of experience: a Kruskal-Wallis test showed no statistical significance difference $(H=5.501, p=$ 0.36 ) in the level of $\mathrm{MI}$ training reported by respondents across the schools of undergraduate training (Table 4).

However, there was a significant difference between the level of training in Ml across the various educational qualifications $(H=12.867, p=0.005)$. Dunn-Bonferroni pair-wise post hoc test showed a significant difference between DPT and Bachelor levels of training $(Z=-109.667, p=0.047)$, other pairs have no significant difference.

\section{Discussion}

The study explored the nature and level of MI training among indigenous-trained physiotherapists in Nigeria. However, there was a paucity of literature on the essence of physiotherapists' diagnostic and 
procedural imaging training. The present research draws most of the comparison from a US-based study by Boissonnault and colleagues [21], which, to the best of our knowledge, appears to be the only published study on the nature of MI curriculum in a countrywide physiotherapy programme.

The inclusion of the standalone MI module in entry-level physiotherapy programme is recent, and curricular emphasis differs across institutions and countries of the world [21, 22]. The potential for the physiotherapists becoming a first-contact provider and the Ml referral-rights granted to them in many countries and practise settings are significant factors that have changed the perception of the importance of $\mathrm{Ml}$ in the education of physiotherapists [4].

The present survey had a similar demographic finding with another online study [23] conducted on the same population. The study reported that $42.5 \%$ of the physiotherapists in Nigeria were in the orthopaedic or musculoskeletal specialty, but the present study reported a slightly higher percentage, $46.3 \%$. The increase could be attributed to a phenomenon by which subject area (musculoskeletal imaging) influences the response rate of an online survey. The age (32 \pm 6 years) of the respondents in the study [23], was similar to (33 \pm 8 years) our study participants. However, our study recorded a female to male response ratio of 1:2 against 1:1 that was reported by Adje and colleagues [23]. A similar study conducted in Ontario, Canada, reported a ratio of 3:1 in favour of females physiotherapists [24]. Interestingly, the finding (male $=68.7 \%$ ) concurred with the report of Balogun and colleagues who posits that physiotherapists in Nigeria are dominated by men, who made up $72 \%$ of university lecturers and $63 \%$ of practicing physiotherapists [25].

Comparatively, the diagnostic imaging curricula of the US-based institutions [21], revealed that their Nigerian counterparts are still deficient. The present study reported that $74.3 \%$ of the respondents received at least one type of $\mathrm{Ml}$ training at the undergraduate, $23.5 \%$ had a standalone course. While in the US, $98.1 \%$ of the $(n=206)$ institutions had incorporated diagnostic imaging in their medical track courses or electives, and $50.0 \%$ had specifically adopted a standalone course [21]. This finding is not surprising; aside from few institutions that took proactive steps, the physiotherapy education programmes in Nigeria did not include a standalone diagnostic imaging course in their curricula [18].

However, the findings in this study showed that the majority of the respondents (51.5\%) received $\mathrm{MI}$ training between the third and fourth (penultimate) years. The outcome is in contrast with a study [21] that reported that $92.7 \%$ of the institutions in the US introduced imaging content in the first or second year of the programme. The American Physical Therapy Association (APTA) recommended an early integration of $\mathrm{Ml}$ knowledge and skills in the DPT educational programme in tandem with the preclinical science contents [16]. As Nigerian institutions prepare to implement the newly approved DPT programme with a standalone diagnostic imaging course [2], the contents should be introduced early in the curriculum.

The results showed that physiotherapists taught $26.3 \%$ of the respondents; radiologists taught $22.0 \%$, both personnel taught another $22.0 \%$, adjutant staff instructed the remaining $4.0 \%$, and $25.7 \%$ were not 
taught MI at entry-level. We are not aware of any previous study that investigated the personnel that delivered the undergraduate MI contents and their qualifications.

An undergraduate clinical posting exposure, which $58.0 \%$ of respondents of this survey received at the diagnostic imaging department of the affiliated hospitals, was in line with best practises in the US. A similar study conducted at the University of Puget Sound in the US reported an average student exposure to imaging during clinical experiences as 43.13 hours and 34 hours of classroom instruction [22]. Hospital-based clinical education is a vital component of entry-level physiotherapy programmes worldwide [26]; the model allows the physiotherapy students to practicalise their theoretical classroom experiences under the supervision of a clinical instructor [27]. Different models of clinical placement or posting, education, and supervision are being researched to determine their impacts on students' achievement [26, 28].

Our findings revealed that only a few physiotherapy departments have started posting interns to the diagnostic imaging department of their hospitals. Consequently, most of the respondents, $92.8 \%$, did not have diagnostic imaging posting exposure. A US-based study recommended for diagnostic imaging exposure during classroom instruction, onsite clinical posting, and full-time internships [22].

Virtually all the respondents (95.5\%) did not receive USS training during the undergraduate and internship programmes. The finding concurred with the point of view by Potter and colleagues that musculoskeletal ultrasound imaging is an advanced-CPD content [17]. Correspondingly, the Federation of State Boards of Physical Therapy (FSBPT) in the US has stated that the ability to perform hands-on USS is not currently an entry-level skill and should require additional CPD [29].

However, the MRTBN has made CPD programmes a prerequisite for the mandatory annual renewal of physiotherapy practicing licence in Nigeria. Therefore, our study excluded respondents without a current practicing licence. Professional associations mainly organise CPD programmes in Nigeria. Yearly, a Nigerian physiotherapist is expected to accrue over 30 CPD points through workshops. A question of interest asked was if these workshops incorporate diagnostic imaging contents.

Respondents were asked how many diagnostic imaging workshops they have ever attended; unfortunately, the majority $(67.3 \%)$ had never participated in any diagnostic imaging workshop. The few respondents that had attended ( 1 to 3 ) such workshops did not have any hands-on experience during the workshops, especially in the area of USS. Our finding corroborated Potter and colleagues [17] who reported that most respondents in their survey indicated that there were inadequate resources to receive supervision to maintain USS CPD, suggesting a lack of appropriately qualified and skilled mentors.

Physiotherapy training institutions in Nigeria have developed postgraduate (M.Sc. and Ph.D.) programmes [30]. The present study focused on the local physiotherapy programme, so those with postgraduate outside the country were excluded. Postgraduate training in Nigeria involves both taken specified physiotherapy and elective courses and research work. Diagnostic imaging was not among the 
core and elective courses in Nigerian postgraduate physiotherapy programmes, contrasting the situation in Canada where postgraduate MI courses were available [24].

Consequently, virtually all the postgraduate respondents neither had clinical postings nor hands-on USS training at that level. In a study $(n=1,574)$ conducted among registered physiotherapists in Ontario, Canada, few respondents had taken postgraduate causes in ordering diagnostic imaging as follows; $5 \%$ plain film X-ray, 4\% each for MRI, diagnostic ultrasound and CT scan [24]. Since some imaging modalities such as procedural and rehabilitative USS is beyond entry-level programme [17, 29], we recommend that postgraduate educational programmes should put more emphasis on them.

Our study explored the self-reported level of MI training among a sample of physiotherapists in Nigeria. The median respondents' rating indicated that training on X-ray was significantly higher than all other modalities, but training on MRI and CT scan were higher than training on USS, scintigraphy, and DEXA. Our findings were consistent with the conclusions of a previous study [22] that exposure to X-ray and MRI were higher in both the didactic portion and clinical experiences when compared with exposure to other modalities.

It is worthy to note that educational programmes in the US have proactively integrated ultrasound imaging content into their curricula $[17,21]$. There is a paucity of literature on physiotherapists' level of training in DEXA and scintigraphy, though some studies opined that physiotherapists are competent in the use of both modalities [7, 12,21]. DEXA is a prerequisite for spinal manipulation in all women and men age 65 and 70 years and older, respectively [16]; therefore, the knowledge of DEXA-referral is essential for the first-contact physiotherapy-practise.

In our study, after adjusting for higher educational qualification, internship training, workshops, specialty, practise setting, and years of experience, there was no significant difference in the level of MI training received by respondents across the institutions. It implies that there was a similarity in the extent of MI education in all entry-level physiotherapy programmes in Nigeria.

Our findings also revealed a significant difference in the level of MI training between DPT and bachelor's degree holders. Thus, supporting the need to transition the bachelor's degree programme to entry-level DPT. A previous study has indicated that the implementation of the DPT in the US resulted in an increased emphasis on imaging as a content area [21]. Similarly, other studies stated that the entry-level DPT programme was designed to provide adequate imaging education to prepare new graduatephysiotherapists for imaging privileges $[4,22]$.

Most of the physical therapy programmes in the US have transitioned into DPT [21]; however, the advocacy for the entry-level DPT education has been ongoing in Nigeria for over three decades [31]. Fortunately, the NUC approved the DPT curriculum in 2018; the emphasis has shifted to speedy implementation. A programme readiness evaluation survey conducted among all the institutions in Nigeria offering physiotherapy educational programme $(n=7)$, showed that the vast majority $(71 \%)$ of 
the universities were ready to implement the DPT curriculum [25]. The few DPT holders $(n=8)$ that participated in our study obtained their DPT training abroad, but with an enormous financial burden.

\section{Limitations}

The subjects were not randomly selected; therefore, our findings cannot be generalised nationally to the physiotherapists in Nigeria. In Nigeria, physiotherapists undergo a mandatory one-year post-entry-level qualification clinical internship programme in an accredited hospital [32]. Nigerian physiotherapy internship programme commenced in 1994. The study excluded respondents who graduated earlier than 1994 and others who did not undergo the training.

However, the study instrument was designed to generate subjective data based on self-reported recall of the respondents' training experiences, using a simple five-point Likert scale. Although the instrument captures the aspect of continuous professional development, we could not rule out all possible interfering exposures between the timeline.

Consequently, the instrument could not objectively quantify the respondents' current level of $\mathrm{MI}$ training, knowledge, skill, or competence; instead, it relied on their perception in retrospect. Nonetheless, a retrospective survey is an acceptable methodology. On the nature of MI training, the PMIPQ did not obtain information on the duration of MI clinical education during the internship programme. It was therefore recommended that PMIPQ should be revised to include this vital information.

\section{Conclusion}

Our study characterised the MI training among the indigenously-educated physiotherapists in Nigeria. Most respondents in this study neither received an entry-level MI standalone course, MI clinical-posting during the internship programme nor participated in any MI CPD programme. Their primary knowledge of MI was acquired mainly as part of clinical instructions in medical track courses. Generally, the selfreported level of MI training among the respondents was inadequate; however, the level of training received across the MI modalities differ, the level of training in X-ray, was significantly higher than the level of training in other MI modalities. Precisely the level of training in USS, DEXA and scintigraphy were reported to be very deficient. Our study also buttressed the call for the implementation of the approved DPT programme in Nigeria, which is expected to bridge the identified gaps in the Ml entry-level training. Further studies should be institution-based and focus on Ml contents and curricular performance.

\section{Abbreviations}

ANOVA: Analysis of Variance

APTA: American Physical Therapy Association

CPD: Continuous Professional Development 
CT scan: Computed Tomography Scan

DEXA: Dual Energy X-ray Absorptiometry

DPT: Doctor of Physical Therapy Programme

M.Sc.: Masters of Science Degree

MRI: Magnetic Resonance Imaging

MRTBN: Medical Rehabilitation Therapists Board of Nigeria

NUC: National Universities Commission, Nigeria

Ph.D.: Doctor of Philosophy Degree

PMIPQ: Physiotherapist's Musculoskeletal Imaging Profiling Questionnaire

t-DPT: Transitional Doctor of Physical Therapy Programme

UK: United Kingdom

URL: Uniform Resource Locator

US: United States

USS: Musculoskeletal Ultrasound Scan

X-ray: Radiography

\section{Declarations}

\section{Ethical approval and consent to participate}

Ethical approval was obtained from the Health Research and Ethics Committee of the Faculty of Health Sciences and Technology, Nnamdi Azikiwe University, Nnewi Campus, Nigeria (Reference number: ERC/FHST/NAU/2018/198). The objectives of the study were clearly explained in the informed consent form and endorsed by each participant.

\section{Consent for publication}

Not applicable.

\section{Availability of data and materials}

The questionnaire used and datasets analysed during the current study are available from the corresponding author on reasonable request. 


\section{Competing interests}

The authors declare that they have no competing interests.

\section{Funding}

There was no external funding for this study.

\section{Authors' contributions}

OKKO, JOU, and MJN contributed to the conception of this study. OKKO, JOU, CIE, JAB, CU, MJN, KIO, BB, IBN, and MEA made substantial contributions to the design, acquisition of data, and performed the statistical analysis. OKKO, CIE, CU, BB and MEA were responsible for drafting the article. JAB, KIO, and IBN contributed to its critical revision. All authors approved the final manuscript for publication. All authors have agreed to be personally accountable for the author's contributions and to ensure that questions related to the accuracy or integrity of any part of the work, even ones in which the author was not personally involved, are appropriately investigated, resolved, and the resolution documented in the literature.

\section{Acknowledgements}

The authors acknowledge Drs. Peter Ibikunle, Christopher Akosile, and Fatai Maruf all from the Department of Medical Rehabilitation, Nnamdi Azikiwe University, Nigeria, and Dr. Mrs. Olufunke Akanle the Registrar/CEO of Medical Rehabilitation Therapists (Registration) Board of Nigeria, for their contributions to this study.

\section{References}

1. World Confederation for Physical Therapy. Policy Statement: Description of Physical Therapy. London: World Confederation for Physical Therapy; 2011.

2. Onyeso OKK, Umunnah JO, Ibikunle PO, Odole AC, Anyachukwu CC, Ezema Cl, Nwankwo MJ. Physiotherapist's musculoskeletal imaging profiling questionnaire: Development, validation, and pilot testing. S Afr J Physiother. 2019; 75(1), a1338. DOI: 10.4102/sajp.v75i1.1338.

3. Zimny NJ. Diagnostic classification and orthopaedic physical therapy practice: what we can learn from medicine. J Orthop Sports Phys Ther. 2004;34:105-109.

4. Keil AP, Baranyi B, Mehta S, Maurer A. Ordering of diagnostic imaging by physical therapists: a 5-year retrospective practice analysis. Phys Ther. 2019;99:1020-1026.

5. Deyle DG. Musculoskeletal imaging in physical therapist practice. J Orthop Sports Phys Ther.2005;35(11):708-21.

6. Agustsson H. Diagnostic Musculoskeletal Imaging: How Physical Therapists Utilize Imaging in Clinical Decision-Making. A Ph.D. dissertation submitted to Department of Physical Therapy, College of Health Care Sciences, Nova Southeastern University; 2018 
[p.148].https://pdfs.semanticscholar.org/c889/f3a39005b66f661ef4486a950bc6f8f33495.pdf. Accessed 20 Dec 2019.

7. Boyles RE, Gorman I, Pinto D, Ross MD. Physical Therapist practice and the role of diagnostic imaging. J Orthop Sports Phys Ther.2011;41(11):829-37.

8. Hillman BJ, Goldsmith JC. The uncritical use of high-tech medical imaging. N Engl J Med. 2010;363:4-6. DOI:10.1056/ NEJMp1003173

9. Gazelle GS, Halpern EF, Ryan HS, Tramontano AC. Utilization of diagnostic medical imaging: comparison of radiologist referral versus same specialty referral. Radiology. 2007;245:517-22.

10. Lehnert BE, Bree RL. Analysis of appropriateness of outpatient CT and MRI referred from primary care clinics at an academic medical center: how critical is the need for improved decision support? J Am Coll Radiol. 2010;7:192-97.

11. Benson CJ, Schreck RC, Underwood FB, Greathouse DG. The role of Army physical therapists as nonphysician health care providers who prescribe certain medications: observations and experiences. Phys Ther. 1995;75(5):380-6.

12. Kersten P, McPherson K, Lattimer V, George S, Breton A, Ellis B. Physiotherapy extended scope of practice-who is doing what and why? Physiotherapy. 2007;93:235-42.

13. Pham HH, Ginsburg PB, McKenzie K, Milstein A. Redesigning care delivery in response to a high performance network: the Virginia Mason Medical Center. Health Affair. 2007;26(4):w532-44.

14. Beling J, Chisati E. Advancing physical therapy practice through curriculum revision: The Malawi experience. Front Public Health. 2017;5:216. DOI: 10.3389/fpubh.2017.00216.

15. Sedgley C. The responsibilities of becoming a physiotherapist. In: Porter S. (ed). Tidy's Physiotherapy. (15th edn). United Kingdom: Churchill Livingstone; 2013:1-21.

16. American Physical Therapy Association. Imaging education manual for Doctor of Physical Therapy professional degree programs. 2015. [58 p.].

https://www.orthopt.org/uploads/content.../DxProclmagPhysTherPractice_FINAL.pdf. Accessed 17 Jun 2016.

17. Potter CL, Cairns MC, Stokes M. Use of ultrasound imaging by physiotherapists: a pilot study to survey use, skills, and training. Man Ther. 2012;(1):39-46. DOI: 10.1016/j.math.2011.08.005. Epub 2011 Sep 28.

18. Medical Rehabilitation Therapists (Registration) Board of Nigeria. Harmonized curriculum of studies for the Bachelor of Physiotherapy (B.PT) degree programme in Nigerian universities. 2009. [27 p.]. http://www.mrtbnigeria.org/docs/curr/BPTCurriculum.pdf. Accessed 17 Jun 2016.

19. Medical Rehabilitation Therapists (Registration) Board of Nigeria. Research and Statistics Unit Report, 2019. Lagos: Medical Rehabilitation Therapists (Registration) Board of Nigeria; 2019.

20. Yamane T. Statistics, an introductory analysis. (2nd edn). New York: Harper and Row; 1976; 886-7.

21. Boissonnault WG, White DM, Carney S, Malin B, Smith W. Diagnostic and procedural imaging curricula in physical therapist professional degree programs. J Orthop Sports Phys Ther. 
2014;44(8):579-86.

22. Sak-Ocbina WC, Lancaster R, Muraoka T, Boyles R. Musculoskeletal imaging education in a doctor of physical program. Proceedings of the 17th Physical Therapy Research Symposium; 2016.[ 2 p.]. http://soundideas.pugetsounds.edu/ptsymposium/17. Accessed 14 Dec 2017.

23. Adje ME, Odebiyi DO, Okafor UAC, Kalu ME (2018). Ergonomic principles in patient handling: Knowledge and practice of physiotherapists. Work. (Pre-Print): 1-8. DOI: 10.3233/WOR-193044.

24. Chong JNK, Goldan S, Zabjek K, De Luca K, Imam A, Chu A, Li B, Yeung B. Ordering diagnostic imaging: A survey of Ontario physiotherapists' opinions on an expanded scope of practice. Physiother Can. 2015;67(2):144-56.

25. Balogun JA, Oyeyemi AY, Balogun AO. Entry-level Doctor of Physiotherapy in Nigeria: Program readiness evaluation. Int J Curr Res. 2017;9(7):54884-91.

26. Odole AC, Oladoyinbo OT. Models of physiotherapy clinical education in South-West Nigeria. SEAJME. 2014;(8)2:35.

27. Ezenwankwo EF, Ezeukwu AO, Abaraogu UO, Manu GP, Mogbolu GA, Ezelioha RN, Ifediora LP, Uchenwoke $\mathrm{Cl}$. Physiotherapy clinical education in the Eastern Nigeria: students' and interns' views on clinical educator characteristics, opportunities, and learning conditions, Eur J Physiother. 2018;21(3):153-63. DOI: 1080/21679169.2018.1503720

28. Barrett EM, Belton A, Alpine LM. Supervision models in physiotherapy practice education: student and practice educator evaluations. Physiother Theory Pract. 2019;11:1-14. DOI: 10.1080/09593985.2019.1692393.

29. Federation of State Boards of Physical Therapy. Rehabilitative ultrasound imaging: A resource guide. 2011.https://www.fsbpt.org/download/2011DH_DelegateHandbook.pdf. Accessed 20 May 2016.

30. Balogun JA, Aka P, Balogun AO, Obajuluwa VA. A phenomenological investigation of the first two decades of university-based physiotherapy education in Nigeria. Cogent Med. 2017;4(1):1301183. DOI:10.1080/2331205X.2017.1301183

31. Medical Rehabilitation Therapists (Registration) Board of Nigeria. Harmonized curriculum of studies for the Transitional Doctor of Physiotherapy (T-DPT) degree programme in Nigerian universities; 2009. [14 p.]. http://www.mrtbnigeria.org/docs/curr/T-DPTCurriculum.pdf. Accessed 14 Dec 2014.

32. Onigbinde AT. The impacts of internship programme and its effects on the physiotherapy practice in Nigeria. Nigerian Journal of Medical Rehabilitation. 2006;11(2):86-91.

\section{Tables}

Table 1 Study participant's demographic profile 


\begin{tabular}{lccc}
\hline Parameter & \multicolumn{2}{c}{ Sex: $n(\%)$} & Total: $f(\%)$ \\
& Male & Female & \\
\hline $\boldsymbol{n}(\%)$ & $275(68.7)$ & $125(31.3)$ & $400(100.0)$ \\
Specialty of Interest & & & \\
Orthopaedic/Musculoskeletal & $132(48.0)$ & $53(42.4)$ & $185(46.3)$ \\
Non-Orthopaedic/Musculoskeletal & $143(52.0)$ & $72(57.6)$ & $215(53.7)$ \\
Highest Qualification & & & \\
Bachelor & $190(69.1)$ & $90(72.0)$ & $280(70.0)$ \\
Doctor of Physical Therapy & $5(1.8)$ & $3(2.4)$ & $8(2.0)$ \\
Masters & $64(23.3)$ & $25(20.0)$ & $89(22.3)$ \\
Doctorate & $16(5.8)$ & $7(5.6)$ & $23(5.7)$ \\
University of Undergraduate Training & & & \\
University A & $27(9.8)$ & $9(7.2)$ & $36(9.0)$ \\
University B & $32(11.6)$ & $16(12.8)$ & $48(12.0)$ \\
University C & $125(45.5)$ & $43(34.4)$ & $168(42.0)$ \\
University D & $24(8.7)$ & $28(22.4)$ & $52(13.0)$ \\
University E & $26(9.5)$ & $12(9.6)$ & $38(9.5)$ \\
University F & $24(8.7)$ & $11(8.8)$ & $35(8.7)$ \\
University G & $17(6.2)$ & $6(4.8)$ & $23(5.8)$ \\
Practise Setting & & & \\
Federal Hospital & $88(32.0)$ & $36(28.8)$ & $124(31.0)$ \\
State/General Hospital & $47(17.1)$ & $27(21.6)$ & $74(18.5)$ \\
Private Hospital & $44(16.0)$ & $16(12.8)$ & $60(15.0)$ \\
Private Physiotherapy Clinic & $47(17.1)$ & $17(13.6)$ & $64(16.0)$ \\
In-home Physiotherapy Service & $22(8.0)$ & $11(8.8)$ & $33(8.3)$ \\
Sports Team & $3(1.1)$ & $3(2.4)$ & $6(1.5)$ \\
University & $13(4.7)$ & $6(4.8)$ & $19(4.7)$ \\
Others & $11(4.0)$ & $9(7.2)$ & $20(5.0)$ \\
\hline & & &
\end{tabular}

The universities were anonymised for ethical reasons.

Table 2 Characteristics of the MI training received by respondents 


\begin{tabular}{|c|c|c|c|c|}
\hline $\begin{array}{l}\text { Parameter } \\
n(\%)\end{array}$ & $\begin{array}{c}\text { Undergraduate } \\
400(100 \%)\end{array}$ & $\begin{array}{c}\text { Postgraduate } \\
112(100 \%)\end{array}$ & $\begin{array}{c}\text { Internship } \\
400 \\
(100 \%) \\
\end{array}$ & $\begin{array}{c}\text { Workshops } \\
400 \\
(100 \%) \\
\end{array}$ \\
\hline \multicolumn{5}{|l|}{ Type of courses offered } \\
\hline Standalone course & $40(10.0)$ & $0(0.0)$ & - & - \\
\hline Medical track courses & $203(50.8)$ & $52(46.4)$ & - & - \\
\hline Both & $54(13.5)$ & $0(0.0)$ & $206(51.5)$ & $131(32.7)$ \\
\hline \multirow[t]{2}{*}{ Not taught } & $103(25.7)$ & $60(53.6)$ & a & $\mathrm{b}$ \\
\hline & & & $194(48.5)$ & $\underset{c}{269 \underset{c}{(67.3)}}$ \\
\hline \multicolumn{5}{|c|}{ Medical tracks or workshops } \\
\hline $1-3$ & $239(59.8)$ & $50(44.6)$ & - & $131(32.7)$ \\
\hline $4-6$ & $12(3.0)$ & $2(1.8)$ & - & $\mathrm{b}$ \\
\hline $7-9$ & $3(0.7)$ & $0(0.0)$ & - & $0(0.0)$ \\
\hline $10 \geq$ & $3(0.7)$ & $0(0.0)$ & - & $\begin{array}{l}0(0.0) \\
0(0.0)\end{array}$ \\
\hline $\begin{array}{l}\text { First-time instruction and } \\
\text { duration }\end{array}$ & Year & Semester & Weeks & Days \\
\hline 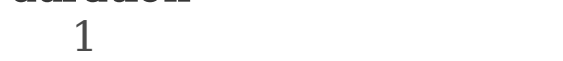 & $9(2.3)$ & $25(22.3)$ & - & - \\
\hline 2 & $23(5.7)$ & $27(24.1)$ & - & - \\
\hline 3 & $90(22.5)$ & $0(0.0)$ & - & - \\
\hline 4 & $116(29.0)$ & $0(0.0)$ & - & - \\
\hline 5 & $59(14.8)$ & $0(0.0)$ & - & - \\
\hline Not taught & $103(25.7)$ & $60(53.6)$ & - & - \\
\hline \multicolumn{5}{|l|}{ Instructional method } \\
\hline Theory only & $114(28.5)$ & $21(18.7)$ & $48(12.0)$ & $31(7.7)$ \\
\hline Practical only & $41(10.3)$ & $24(21.4)$ & $110(27.5)$ & $30(7.5)$ \\
\hline Both & $142(35.5)$ & $7(6.3)$ & $48(12.0)$ & 70 (17.5) \\
\hline Not taught & $103(25.7)$ & $60(53.6)$ & $194(48.5)$ & $\begin{array}{c}269 \underset{c}{(67.3)} \\
\text { (6) }\end{array}$ \\
\hline \multicolumn{5}{|l|}{ Teaching personnel } \\
\hline Physiotherapist & $105(26.3)$ & $35(31.2)$ & $156(39.0)$ & $12(3.0)$ \\
\hline Radiologist & $88(22.0)$ & $10(8.9)$ & $6(1.5)$ & 79 (19.7) \\
\hline Both & $88(22.0)$ & 7 (6.3) & $32(8.0)$ & $40(10.0)$ \\
\hline Others & $16(4.0)$ & $0(0.0)$ & $12(3.0)$ & $0(0.0)$ \\
\hline Not taught & $103(25.7)$ & $60(53.6)$ & $194(48.5)$ & $\begin{array}{c}269 \underset{c}{(67.3)} \\
\text { c }\end{array}$ \\
\hline \multicolumn{5}{|l|}{ Clinical posting in DID } \\
\hline Yes & $232(58.0)$ & $10(8.9)$ & $29(7.2)$ & - \\
\hline No & $168(42.0)$ & $102(91.1)$ & $371(92.8)$ & - \\
\hline \multicolumn{5}{|l|}{ Hands-on training in USS } \\
\hline Yes & $18(4.5)$ & $5(4.5)$ & $18(4.5)$ & $38(9.5)$ \\
\hline No & $382(95.5)$ & $107(95.5)$ & $382(95.5)$ & $362(90.5)$ \\
\hline
\end{tabular}

Medical track $=$ Courses that are not focused on MI but contains some MI correlates or instructions, e.g., Anatomy and Orthopaedics. DID = Diagnostic Imaging (clinical) Department; USS = Ultrasound scan.

- = data was not obtained or not applicable.

$\mathrm{a}=$ Respondents that were taught MI while on internship under senior colleagues. 
$\mathrm{b}=$ Respondents that attended at least a workshop with main- or sub-topic on MI.

${ }^{\mathrm{c}}=$ Respondents that have never attended any workshop on MI.

Table 3 Friedman ANOVA: differences in the level of training in MI modalities

\begin{tabular}{|c|c|c|c|c|c|}
\hline Diagnostic Imaging Modality. & $\mathbf{N}$ & $\begin{array}{c}\text { Median } \\
(1-5)\end{array}$ & $\begin{array}{l}\text { Mean } \\
\text { Rank } \\
\end{array}$ & $\begin{array}{c}\text { Friedman Test } \\
{\left[\chi^{2}(15)\right]}\end{array}$ & $P$-value \\
\hline Radiography (X-ray). & 400 & 3 & 5.63 & 1285.899 & $0.001 * *$ \\
\hline $\begin{array}{l}\text { Magnetic Resonance Imaging } \\
\text { (MRI). }\end{array}$ & 400 & 2 & 4.09 & & \\
\hline Computed tomography (CT Scan). & 400 & 2 & 3.72 & & \\
\hline Ultrasound Scan (USS). & 400 & 1 & 2.61 & & \\
\hline Scintigraphy (bone scan). & 400 & 1 & 2.55 & & \\
\hline $\begin{array}{l}\text { Dual Energy X-Ray Absorptiometry } \\
\text { (DEXA). }\end{array}$ & 400 & 1 & 2.40 & & \\
\hline
\end{tabular}

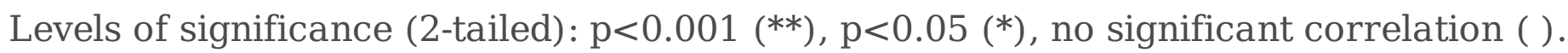
Wilcoxon signed-rank Bonferroni Adjusted Post Hoc test was reported in-text.

Table 4 Kruskal-Wallis: differences in the level of MI training across schools of undergraduate training and various educational qualifications 


\begin{tabular}{|c|c|c|c|c|c|}
\hline $\begin{array}{l}\text { Level of imaging training } \\
\text { across: }\end{array}$ & $\begin{array}{l}N= \\
155\end{array}$ & $\begin{array}{c}\text { Median (6 - } \\
\text { 30) }\end{array}$ & $\begin{array}{l}\text { Mean } \\
\text { Rank }\end{array}$ & $\begin{array}{l}\text { Kruskal-Wallis } \\
(\mathrm{H})\end{array}$ & $\begin{array}{c}\mathrm{p}- \\
\text { value }\end{array}$ \\
\hline University Attended & & & & $8.530^{a}$ & 0.202 \\
\hline University A & 10 & 11.50 & 96.25 & $5.501 \mathrm{~b}$ & 0.358 \\
\hline University B & 12 & 11.00 & 81.92 & & \\
\hline University C & 77 & 10.00 & 71.75 & & \\
\hline University D & 18 & 10.00 & 72.00 & & \\
\hline University E & 12 & 11.00 & 94.83 & & \\
\hline University F & 16 & 9.00 & 72.69 & & \\
\hline University G & 10 & 11.00 & 102.30 & & \\
\hline Highest Qualification & & & & 12.867 & $0.005^{*}$ \\
\hline Bachelor & 280 & 10.00 & 194.64 & & \\
\hline $\mathrm{DPT}$ & 8 & 18.50 & 304.31 & & \\
\hline Masters & 89 & 10.00 & 195.20 & & \\
\hline Doctorate & 23 & 11.00 & 256.30 & & \\
\hline
\end{tabular}

Levels of significance (2-tailed): $\mathrm{p}<0.001$ (**) $^{(* \mathrm{p}<0.05}(*)$, no significant correlation ( ). Dunn-Bonferroni Post Hoc test was reported in-text.

The universities were anonymised for ethical reasons.

a. Adjusted for higher educational qualification, internship training, and workshops

b Adjusted for higher educational qualification, internship training, workshops, specialty, practise setting, and years of experience.

\section{Figures}




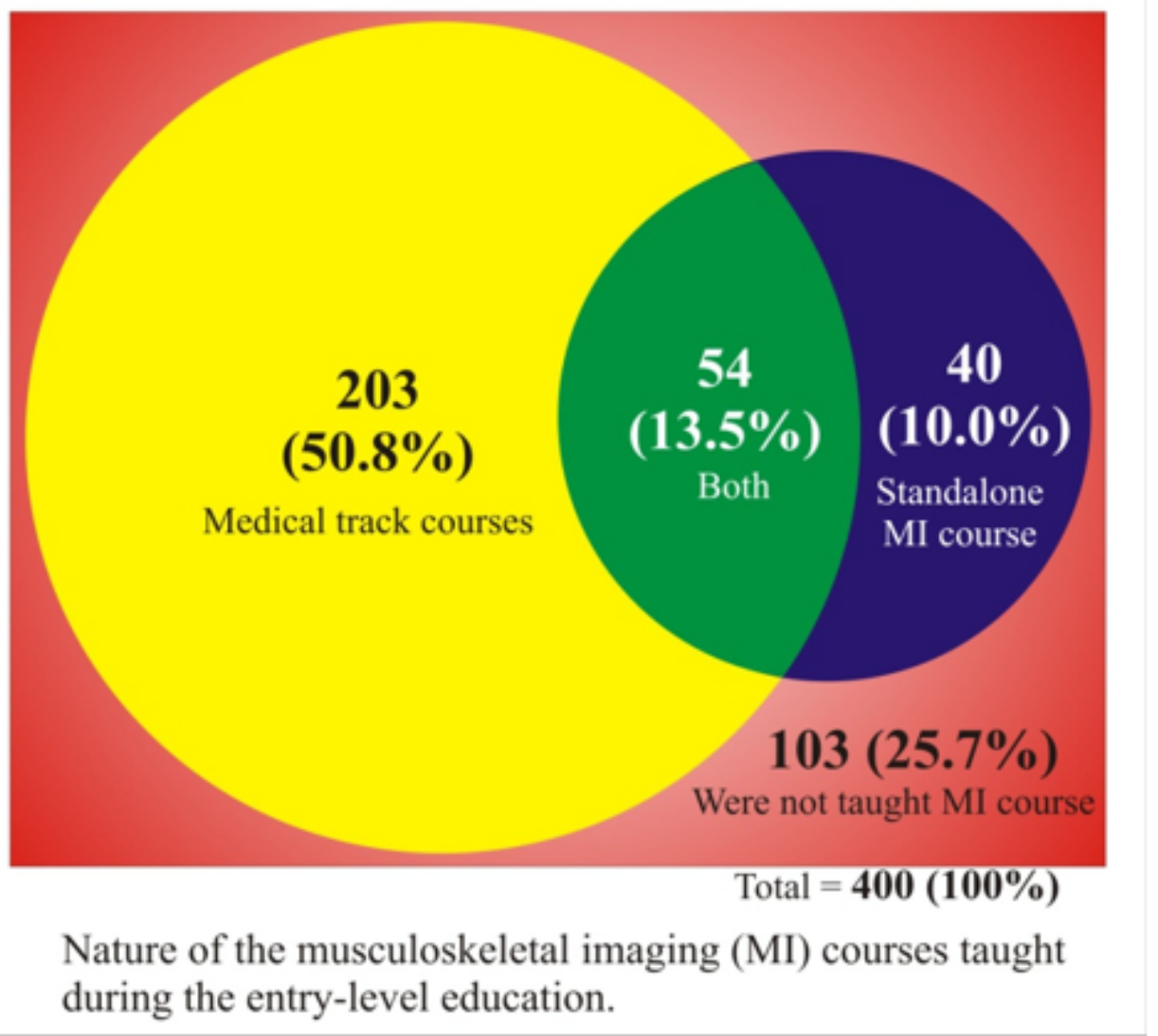

\section{Figure 1}

Venn diagram of the Ml courses taught during the undergraduate education 


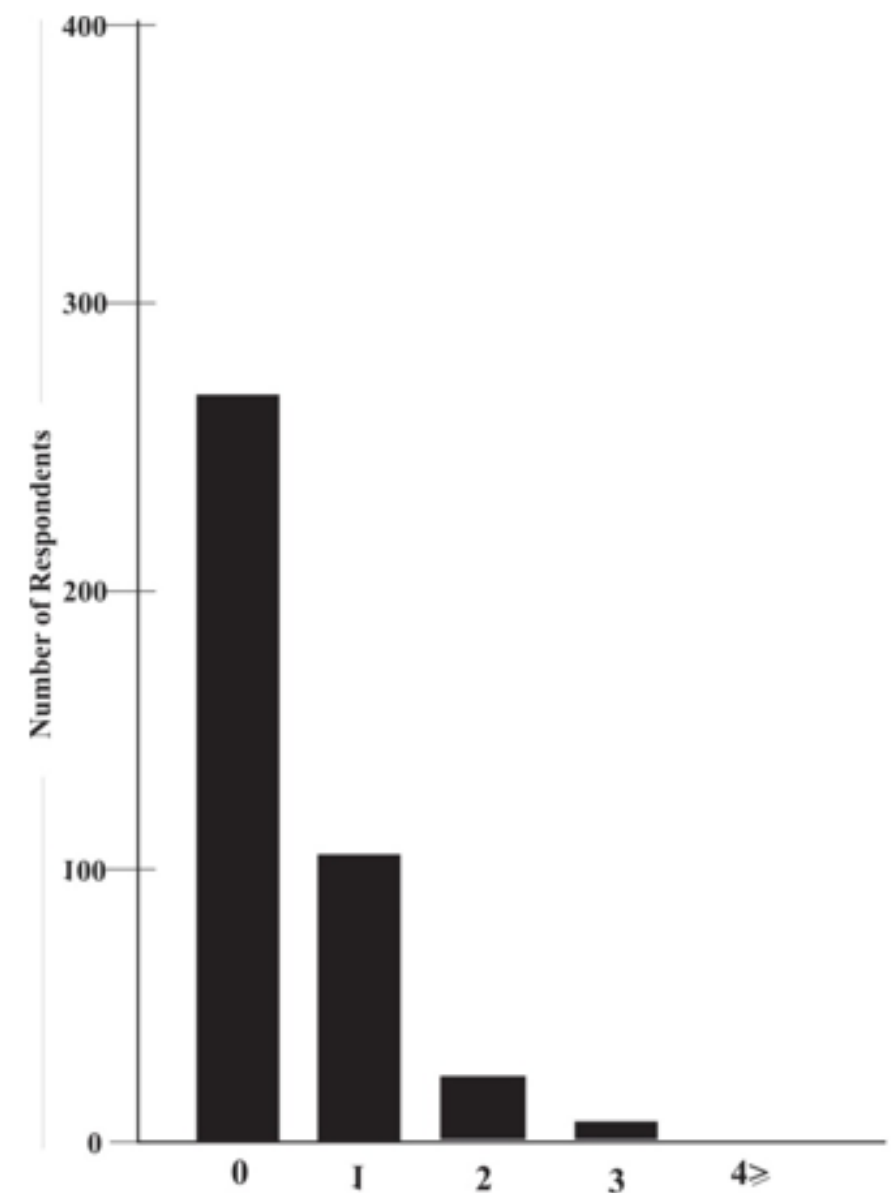

Total Number of diagnostic imaging workshop attended by each respondent

Figure 2

Number of diagnostic imaging workshops ever attended by the respondents 


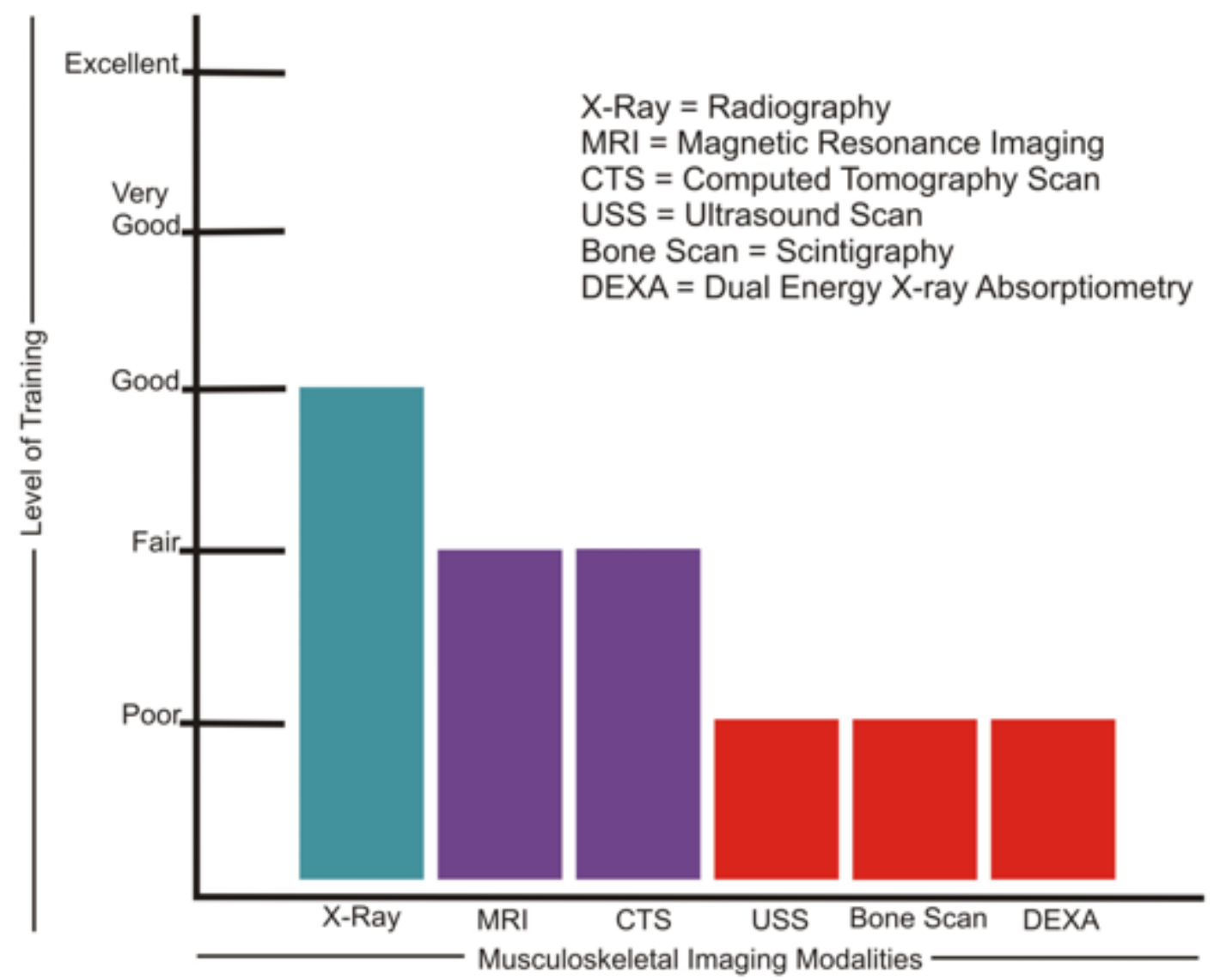

Figure 3

Level of training in interpretation and utilisation of musculoskeletal imaging 